\title{
Case of Human Infestation with Dermanyssus gallinae (Poultry Red Mite) from Swallows (Hirundinidae)
}

\author{
Georgios Sioutas $^{1}\left(\mathbb{D}\right.$, Styliani Minoudi ${ }^{2}$, Katerina Tiligada ${ }^{3} \mathbb{D}$, Caterina Chliva ${ }^{4,5}$, Alexandros Triantafyllidis ${ }^{2}$ (D) \\ and Elias Papadopoulos $1, * \mathbb{D}$
}

1 Laboratory of Parasitology and Parasitic Diseases, School of Veterinary Medicine, Faculty of Health Sciences, Aristotle University of Thessaloniki, 54124 Thessaloniki, Greece; Gsioutas@vet.auth.gr

2 Department of Genetics, Development and Molecular Biology, School of Biology, Aristotle University of Thessaloniki, 54124 Thessaloniki, Greece; sminoudi@bio.auth.gr (S.M.); atriant@bio.auth.gr (A.T.)

3 Department of Pharmacology, Medical School, National and Kapodistrian University of Athens, 10679 Athens, Greece; aityliga@med.uoa.gr

4 Allergy Unit "D. Kalogeromitros", 2nd Department of Dermatology and Venereology, National and Kapodistrian University of Athens, 12462 Athens, Greece; cchliva@gmail.com

5 Medical School, University General Hospital "ATTIKON", 12462 Athens, Greece

* Correspondence: eliaspap@vet.auth.gr; Tel.: +30-69-4488-2872

Citation: Sioutas, G.; Minoudi, S.; Tiligada, K.; Chliva, C.; Triantafyllidis, A.; Papadopoulos, E. Case of Human Infestation with Dermanyssus gallinae (Poultry Red Mite) from Swallows (Hirundinidae). Pathogens 2021, 10, 299. https://doi.org/10.3390/ pathogens10030299

Academic Editor: Stefania Perrucci

Received: 12 February 2021

Accepted: 28 February 2021

Published: 4 March 2021

Publisher's Note: MDPI stays neutral with regard to jurisdictional claims in published maps and institutional affiliations.

Copyright: (c) 2021 by the authors. Licensee MDPI, Basel, Switzerland. This article is an open access article distributed under the terms and conditions of the Creative Commons Attribution (CC BY) license (https:/ / creativecommons.org/licenses/by/ $4.0 /)$.

\begin{abstract}
Dermanyssus gallinae (the poultry red mite, PRM) is an important ectoparasite in the laying hen industry. PRM can also infest humans, causing gamasoidosis, which is manifested as skin lesions characterized by rash and itching. Recently, there has been an increase in the reported number of human infestation cases with D. gallinae, mostly associated with the proliferation of pigeons in cities where they build their nests. The human form of the disease has not been linked to swallows (Hirundinidae) before. In this report, we describe an incident of human gamasoidosis linked to a nest of swallows built on the window ledge of an apartment in the island of Kefalonia, Greece. Mites were identified as D. gallinae using morphological keys and amplifying the Cytochrome C oxidase subunit I (COI) gene by PCR. Bayesian phylogenetic analysis and median-joining network supported the identification of three PRM haplogroups and the haplotype isolated from swallows was identical to three PRM sequences isolated from hens in Portugal. The patient was treated with topical corticosteroids, while the house was sprayed with deltamethrin. After one week, the mites disappeared and clinical symptoms subsided. The current study is the first report of human gamasoidosis from PRM found in swallows' nest.
\end{abstract}

Keywords: Dermanyssus gallinae; gamasoidosis; poultry red mite; swallows; COI gene; PCR; avian mite dermatitis; Greece

\section{Introduction}

The arthropod parasite Dermanyssus gallinae (De Geer 1778), also known as the poultry red mite (PRM), is one of the most important ectoparasites in the modern laying hen industry with a worldwide distribution [1]. Through its blood-sucking action, it is responsible for annual financial losses of about 231 million euros in Europe that are mainly attributed to the resulting reduced egg production and quality and increased morbidity and bird mortality due to anemia [2]. In addition, the PRM has been reported to carry or act as a vector of important zoonotic pathogenic microorganisms, including bacteria Salmonella enteritidis [3,4], Erysipelothrix rhusiopathiae [5], Chlamydia psittaci [6], Escherichia coli [7], Pasteurella multocida, Coxiella burnetii, and Listeria monocytogenes [8], and influenza type A virus [9]. However, for most pathogens, only isolation has been proven from PRM infesting hens. Vectorial competence remains to be demonstrated for some in order to clarify its medical significance in transmission to humans. In relation to urban cases of gamasoidosis, Borrelia burgdorferi sensu lato and Coxiella burnetii have also been isolated 
from D. gallinae [10]. Moreover, the DNA of Bartonella quintana was isolated from PRMs infesting a family house, whose members showed symptoms of trench fever [11].

The genus Dermanyssus includes at least 25 species [12]. Specifically, in the D. gallinae complex, at least 2 clades have been described that are organized in several genealogical series [13]. The different haplotypes that have been identified allow the genetic discrimination between the special lineage L1 of $D$. gallinae that infests mainly urban pigeons (Columba livia domestica) and other Columbiformes species and the D. gallinae sensu stricto that infests hens (Gallus gallus domesticus) and swallows (Hirundinidae) among others. Both cryptic species can infest humans, with $D$. gallinae L1 having more medical relevance in urban areas, where pigeons and doves are common, and D. gallinae sensu stricto usually on poultry farms where hens are housed [14-16]. D. gallinae infests more than 30 wild bird species but has no strict host specificity compared to other Dermanyssus species, which do not alternate between hosts as easily. The increasing incidences of PRM attacks beyond birds indicates expansion to other hosts [12,14]. Global warming, travelling, and increases in the human population, farms, and small animal densities are all thought to facilitate further host expansion [17].

During the day, D. gallinae hides in cracks, crevices, or nests away from light where birds cannot peck and eat them. Its life cycle is direct, and under ideal conditions of temperature $\left(10-35^{\circ} \mathrm{C}\right)$ and relative humidity $(>70 \%)$, it is completed within seven days, causing the formation of large colonies and rapid increases in the population. Contrary to the larvae with six legs that do not engorge in blood, the nymphs and adults have eight legs and are hematophagous. Adults feed at night for less than $2 \mathrm{~h}$ every 2-3 days and turn red after engorging in blood. Females can reach a length of $1 \mathrm{~mm}$ and lay their eggs shortly after a meal. They survive up to eight months without feeding [1,18], but when the host birds are absent, as is the case of abandoned nests by the young pigeons, large PRM populations can forage short distances or relocate to a new food source in search of a blood meal, utilizing temperature stimuli, response to vibrations, and carbon dioxide to locate their host [19].

Most gamasoidosis cases are reported in late spring or early summer [20,21]. Workers at infested poultry houses are at a higher risk for gamasoidosis, described as an "occupational hazard" in their work field [22]. In the urban environment, gamasoidosis cases are associated with the proliferation of pigeons in cities where they build their nests on roofs, air-conditioning boxes, window sills, eaves, and air ducts [20,21,23]. Gamasoidosisis is mainly caused by D. gallinae, but other species, such as Ornithonyssus sylviarum (northern fowl mite), O. bursa (tropical fowl mite), and D. avium may also be causative agents [24]. The resulting PRM-associated dermatitis is a local or generalized non-characteristic skin reaction that may be misdiagnosed as scabies or pediculosis [25]. Skin lesions are usually flattened erythematous papules, intensely pruritic that may affect various parts of the body. Dermatoscopic criteria for the disease have not been described, but dermatoscopy may help rule out delusional parasitoses [26]. The clinical signs are self-limited and usually resolve abruptly, although symptomatic treatment with topical corticosteroids and local or oral antihistamines has been reported [25]. On the other hand, prevention is based on strict monitoring of the infestation site, on the removal of bird nests containing PRM, and on the cleaning and disinfection of the infested area with an appropriate acaricide [16,21].

To the authors' knowledge, there are only limited reports in the available literature on D. gallinae in swallows (Hirundinidae) or their nests, as swallows are typically infested with $D$. hirundinis. In a report from France, D. gallinae constituted $16 \%$ of the Dermanyssus mites found in the swallows' nests [12]. In a second report, D. gallinae was identified in 61 out of 161 (approx. 38\%) barn swallows' nests (Hirundo rustica) examined for mites in Iran [27]. In both reports, most nests were built near or right next to poultry houses, suggesting a migration of PRM from hens to swallows. 


\section{Case Presentation}

\subsection{Clinical Description}

A gamasoidosis case was recently recorded in Argostoli, the capital of the Ionian island of Kefalonia, Greece. A 37-year-old male agronomist presented with scattered groups of pruritic, erythematous papules with a size of $3 \mathrm{~mm}$ and a central punctum in various parts of his body, including the upper and lower limbs. The lesions appeared suddenly in mid-May 2020, especially in the morning hours after waking up, and continued to develop for just over a month (Figure 1).

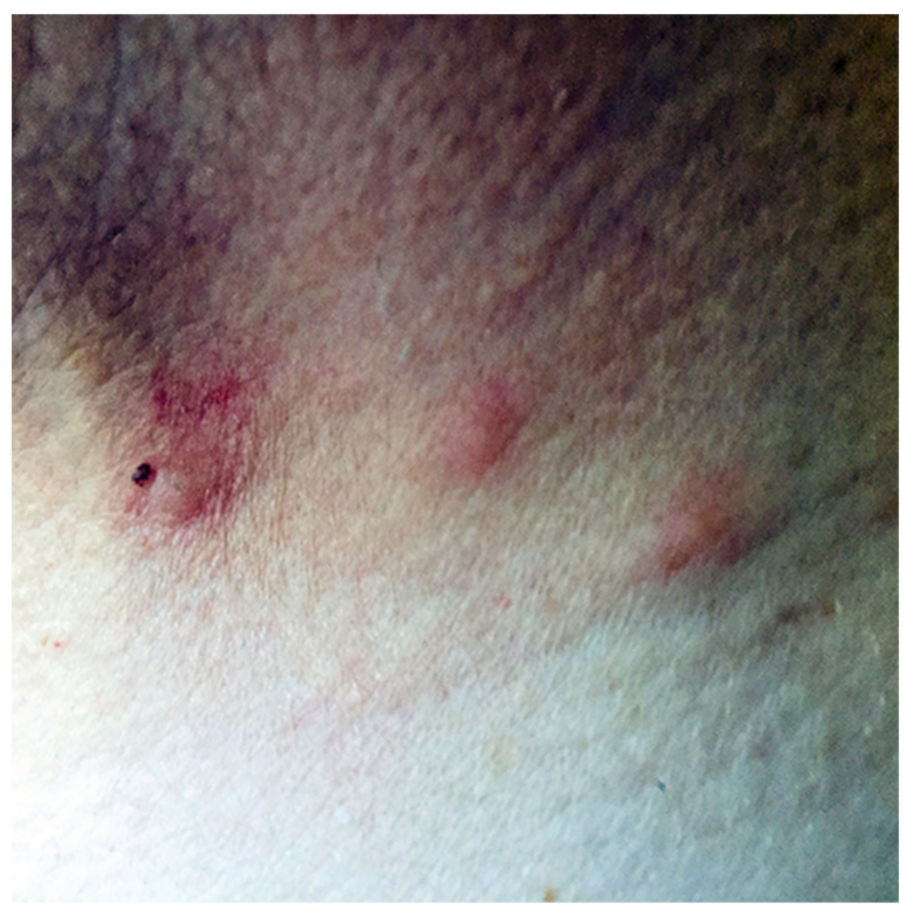

Figure 1. Skin lesions of gamasoidosis following human infestation with Dermanyssus gallinae. Excoriated erythematous papules and urticaria-like plaques characterized by rash and itch developed within minutes after the bites.

The patient visited the emergency department of the local public hospital. He reported that he had experienced more than 20 repeated bites and that local urticarial rash and edema developed within minutes after the bites. Apart from the cutaneous lesions, clinical signs and symptoms from other systems were not reported. There was no personal or family history of any allergic disease, no previous experience of a hypersensitivity reaction, no contact with animals in his daily life, and no pets in the apartment.

In the weeks prior to the onset of the symptoms, the patient had noticed swallows building their nest on the window sill of his privately owned second-floor apartment. A few days after the onset of the symptoms, the patient saw mites crawling in the room and on his body, whereas large mite numbers were present in the swallows' nest. After contacting the Laboratory of Parasitology and Parasitic Diseases, School of Veterinary Medicine, Aristotle University of Thessaloniki, Greece, the patient was instructed to provide a sample of mites in vials containing ethanol $(70 \% v / v)$ as a preservative, as well as to fill in a medical history questionnaire (Figure S1).

\subsection{Morphological Identification of the Mites}

The collected mites were mounted on slides using lactophenol as the mounting medium. After examination under the stereomicroscope (Olympus, Research Stereomicroscope System SZH10) and the light microscope (Olympus, CX21 Microscope) at 100 $\times$ and $400 \times$ magnification using key morphological criteria [28-30], the mites were identified as 
D. gallinae (Figure 2). Further distinction of D. gallinae between the two major linage clades requires DNA analysis [13] and it was not possible to be performed based solely on the morphology. In the reported case, amplification of the Cytochrome $\mathrm{C}$ oxidase subunit I (COI) gene by the polymerase chain reaction (PCR) was used as a marker as proposed by Chu et al. [31].

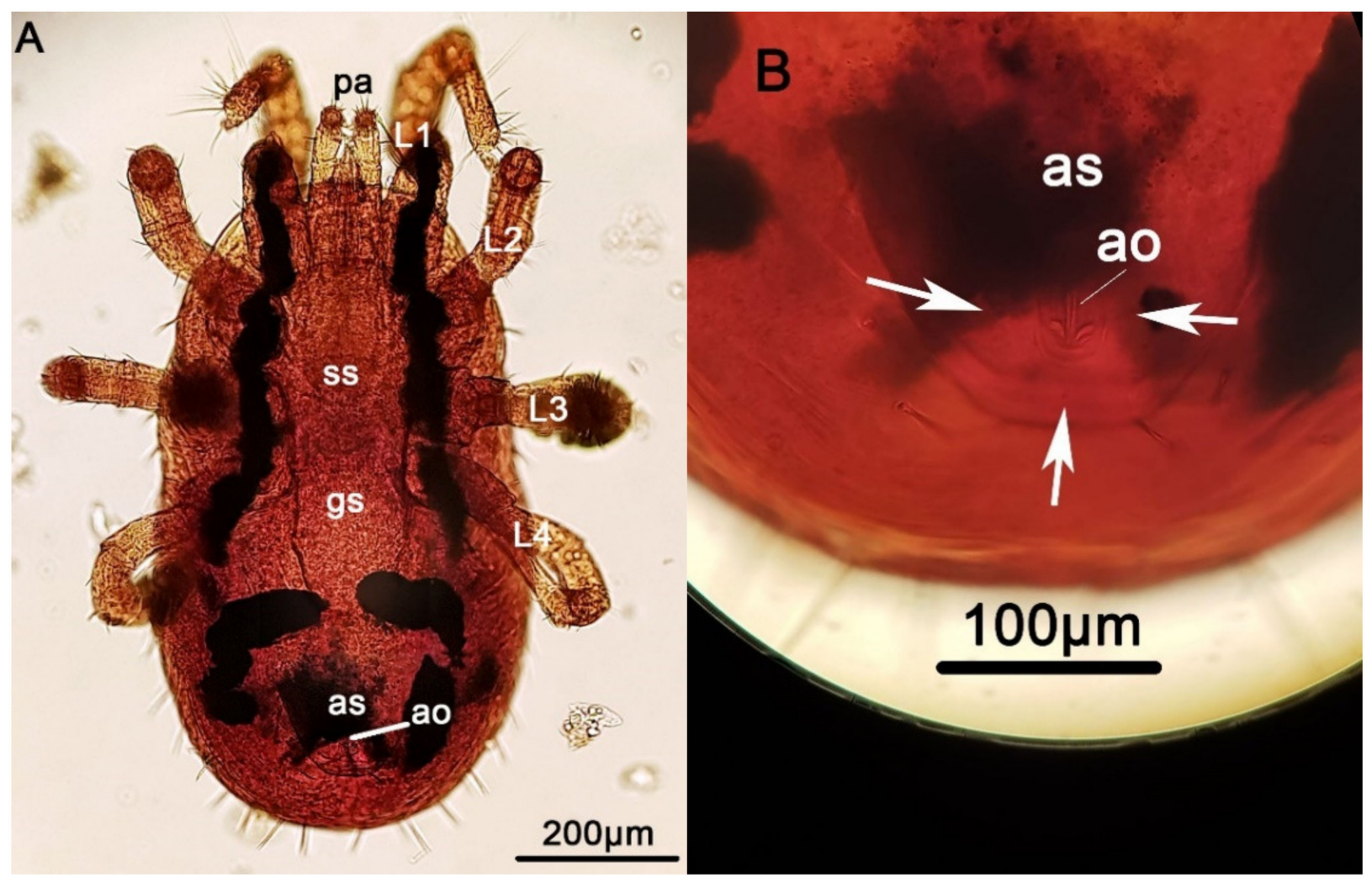

Figure 2. Ventral view of a female Dermanyssus gallinae mite under the light microscope at (A) $100 \times$ magnification and (B) $400 \times$ magnification, detail of the anal shield. Terminology based on keys described by Moss et al. [28,29] and Di Palma et al. [30]: as: anal shield; ao: anal opening; gs: genitoventral shield; ss: sternal shield; L1-4: leg pairs; pa: palp. The arrows pinpoint at the three anal setae.

\subsection{Molecular Identification and Phylogenetic Analysis of the Mites}

Total genomic DNA was extracted from 5 individuals mites using QIAamp DNA mini kit Extraction Kit (Qiagen, Hilden Germany), with some modifications. Mites were homogenized by cutting open their whole body with a sterile Agani ${ }^{\mathrm{TM}} 21 \mathrm{G} \times 1 \frac{1}{2}{ }^{\prime \prime}(0.8 \times 38 \mathrm{~mm})$ needle. The proteinase $\mathrm{K}$ digestion step was performed overnight at $56^{\circ} \mathrm{C}$, and the volumes of all the reagents were modified as follows: $90 \mu \mathrm{L}$ of ATL buffer, $10 \mu \mathrm{L}$ of proteinase $\mathrm{K}, 100 \mu \mathrm{L}$ of $\mathrm{Al}$ buffer, $100 \mu \mathrm{L}$ of ethanol, $250 \mu \mathrm{L}$ of AW1 buffer, and $350 \mu \mathrm{L}$ of AW2 buffer. Extracted DNA was eluted in $50 \mu \mathrm{L}$ of $\mathrm{AE}$ buffer and stored at $-20^{\circ} \mathrm{C}$ until PCR amplification.

A fragment of $681 \mathrm{bp}$ of the COI gene (Cytochrome C oxidase subunit I) of mitochondrial DNA (mtDNA) was amplified using primers COI1Fyuw114 and COI1Ryuw114 [32]. The total volume of PCR reaction was $30 \mu \mathrm{L}$ consisting of $100 \mathrm{ng}$ of genomic DNA as a template, 0.05 units of Qiagen Taq polymerase (Qiagen, Hilden Germany), $2 \mathrm{mM}$ deoxynucleotide triphosphates (dNTPs), $0.3 \mu \mathrm{L}$ of each primer $(100 \mu \mathrm{M}), 2.5 \mathrm{mM} \mathrm{MgCl}_{2}$ (Qiagen, Hilden Germany), and $3 \mu \mathrm{L}$ of $10 \times$ Reaction Buffer (Qiagen, Hilden Germany). A Takara PCR Thermal Cycler (Takara BIO INC, Japan) was used and amplification conditions were the following: initial denaturation at $95^{\circ} \mathrm{C}$ for $5 \mathrm{~min}, 38$ cycles of strand denaturation at $95^{\circ} \mathrm{C}$ for $30 \mathrm{~s}$, annealing at $55^{\circ} \mathrm{C}$ for $45 \mathrm{~s}$, and primer extension at $72{ }^{\circ} \mathrm{C}$ for $30 \mathrm{~s}$, before a final elongation of $5 \mathrm{~min}$ at $72{ }^{\circ} \mathrm{C}$. Amplification success was assessed by electrophoresis of 
the PCR products in 1.5\% (m/v) agarose gels (AppliChem, Darmstadt, Germany) with subsequent visualization under ultraviolet light. All PCR products were sent to the company Genewiz (Takeley, Essex, UK) for purification and sequencing.

Sequences were checked and analyzed using Geneious version 10.2.6 [33]. Sequence data from the present study were combined with 298 COI sequences of D. gallinae isolated from hens (195 sequences: LR812140, LR812284-LR812477 from [32], 103 sequences: LC029457-LC029557 from [31]), 2 sequences of D. gallinae isolated from swallows (AM921866-7 from [13]), 3 sequences isolated from pigeons (AM921859, AM921859 from [13], LT714694 from [16]), and 8 sequences of D. hirundinis isolated from swallows (FM179366, FM179369, AM921872 from [13], FM208740-1, FM208726-8 from [12]). The overlapping region was $457 \mathrm{bp}$.

All the sequences were aligned using Clustal W [34]. The different haplotypes were found by using the program DNAsp v6 [35]. The best-fit nucleotide substitution model for this dataset was determined using MEGA X [36]. The HKY + G model was used for Bayesian phylogeny analysis, carried out with Beast 1.10.4 [37]. The Bayesian tree was constructed using a strict clock model and a coalescent tree prior. The analysis was run for $10^{8}$ Markov Chain Monte Carlo (MCMC) generations, sampled every $10^{4}$ generations. Convergence of chains was visualized using Tracer 1.7 [38] discarding the first 20\% of trees as burn-in. Effective Sample Size (ESS) values for all parameters were larger than the threshold value of 200 identified by Tracer v.1.7. The trees produced by Beast were then summarized in TreeAnnotator 1.10.4 and visualized in FigTree 1.4.3 [39].

Additionally, a median-joining network [40] was constructed using the software Network 10.2.0 and the frequencies of the sequences (Fluxus Technology) assuming equal weights for all mutations and setting the genetic distance parameter to zero in order to restrict the choice of feasible links in the final network.

DNA sequencing was successful in four out of five samples. We obtained a single 529-bp DNA sequence (haplotype) from all four mite individuals. The haplotype we recovered was also the same as three identical sequences from mites isolated from hens in Portugal (Accession numbers: LR812310-2) [32]. The sequence identified in the present study was deposited in GenBank with Accession number: MW542575.

The Bayesian phylogenetic analysis (Figure 3A) and the median-joining network (Figure 3B) supported the identification of three haplogroups as regards clustering haplotypes coming from mites D. gallinae sensu stricto isolated from hens. Haplogroup A contains 23 haplotypes from 10 countries, including the unique haplotype identified in the present study. All mite haplotypes $(n=5)$ previously identified in Greece from Karp-Tatham et al. [32], corresponding to 61 sequences, are also grouped in this cluster. Haplogroup B includes 27 haplotypes from 8 different countries. Finally, haplogroup C includes 10 haplotypes coming from 7 countries. The haplotypes of D. gallinae isolated from swallows clustered in one distinct haplogroup (D), which was separated by several mutational steps $(n=32)$ by the other haplogroups of the species. The special lineage L1 contains haplotypes from D. gallinae mites isolated only from pigeons. The haplotypes of D. hirundinis construct one more distinct haplogroup $(\mathrm{H})$. According to the median-joining network, the two species (D. gallinae sensu stricto and D. hirundinidis) are separated by 55 mutational steps. All accession numbers and countries of origin for each haplotype used in the current study are presented in Table S1. 


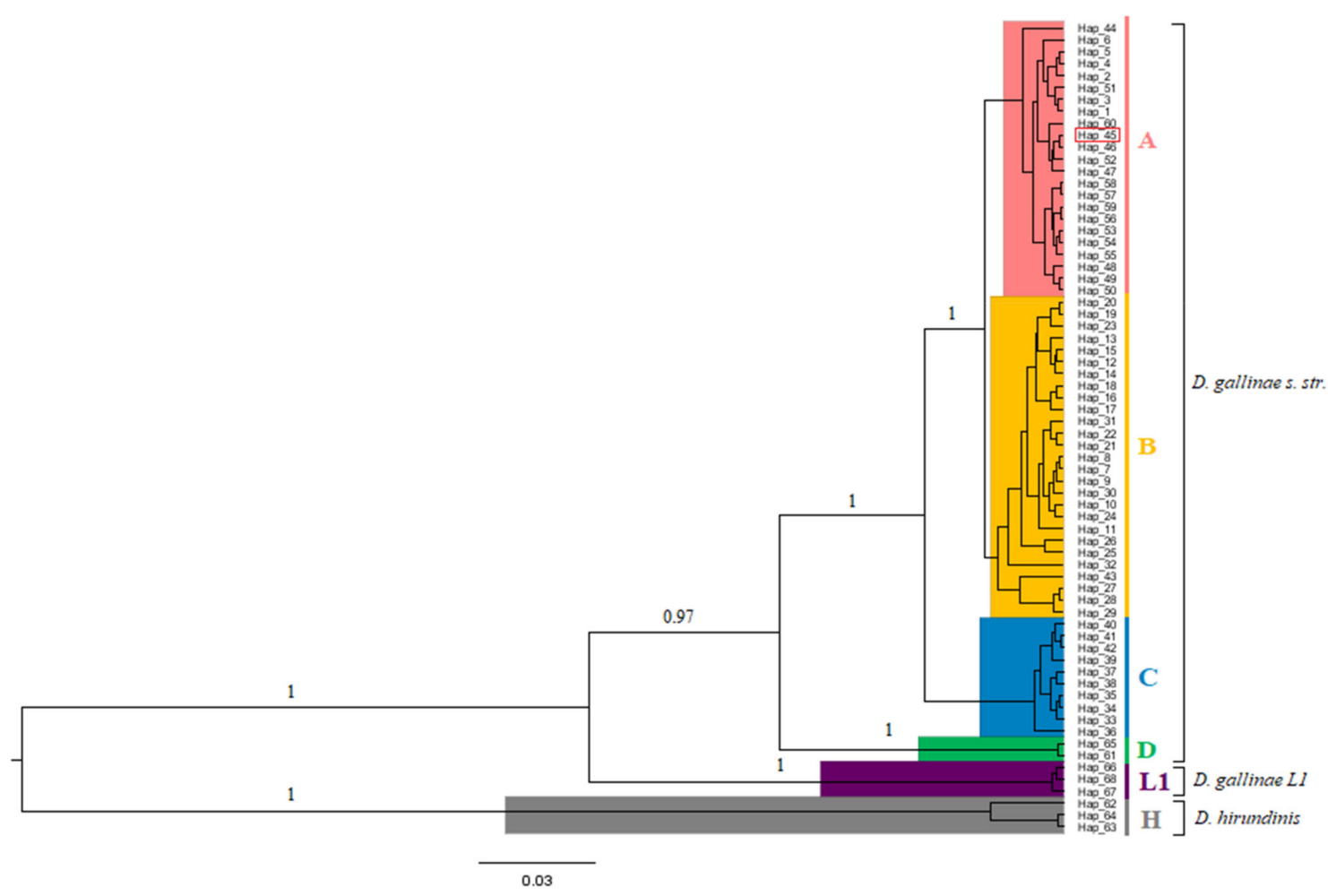

(A)

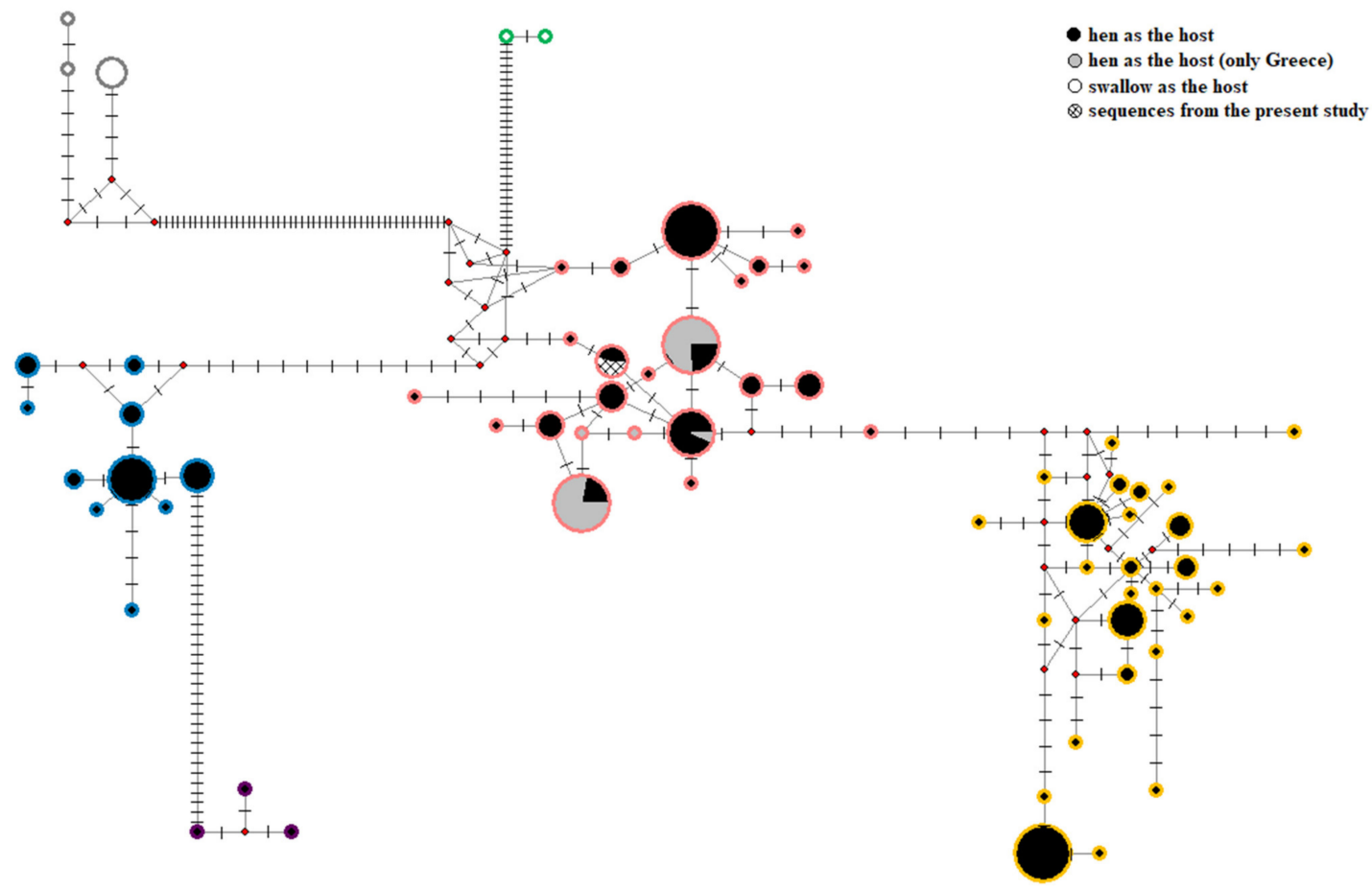

(B)

Figure 3. Haplogroups A (red), B (yellow), C (teal), and D (green) constitute Dermanyssus gallinae sensu stricto cryptic species and haplogroup L1 (purple), Dermanyssus gallinae L1 cryptic species. Haplogroup H (gray) represents Dermanyssus hirundinis. Mites belonging to haplogroup A (red), B (yellow), and C (teal) have been isolated from hens, haplogroup D (green), and H (gray) from swallows, and haplogroup L1 (purple) from pigeons. The single haplotype identified in the current study (haplotype 45) fits in haplogroup A (red) and is highlighted accordingly. (A) Bayesian phylogenetic tree of mites' haplotypes. Posterior probabilities are shown to the main clades. (B) Median-joining network of mtDNA mites' haplotypes. The proportional size of nodes indicates the frequency of haplotypes. The colored line of circles corresponds to the colored haplogroups in the phylogenetic tree (Figure 3A). Small red dots represent inferred haplotypes. 


\subsection{Treatment and Control of the Mite Infestation}

After visiting the emergency department of the local public hospital, the patient was prescribed $0.1 \% \mathrm{w} / \mathrm{w}$ cream methylprednisolone aceponate as topical corticosteroid treatment. Following the identification of the causative agent, thorough cleaning and vacuuming of the apartment was recommended, as well as thorough spraying for a few days with a commercial insecticide formulation, containing 2.5\% deltamethrin (Deltamethrin 2.5 WP, FARMA-CHEM SA, Thessaloniki, Greece; 4-6 g/ $\mathrm{L} \mathrm{H}_{2} \mathrm{O}$, sprayed onto 8-12 m² surface area; application only when mites are seen according to the manufacturer's instructions). The choice of deltamethrin was based on its previous reported success in combating D. gallinae infestations and on experts' recommendations [16,41]. These measures were applied together with the removal from the skin by bathing of any mites crawling on the patient and treatment with topical corticosteroids. After about 1 week, no mites were detected in the apartment and the clinical symptoms subsided. During the following month, no mites were spotted in the apartment and no symptom recurrence was reported by the patient. In the meantime, the young swallows had fledged their nest and did not return, so the owner could finally spray the swallows' nest with deltamethrin to eliminate any remaining mites.

\section{Discussion}

Previous cases of human gamasoidosis have been linked to $D$. gallinae L1 mites infesting pigeons [16,42] and D. gallinae sensu stricto mites from hens [43]. It is uncommon for swallows to be infested with the PRM, since they are usually infested with D. hirundinis [12]. Moreover, this is the first reported human gamasoidosis case caused by D. gallinae due to an infested swallows' nest.

In Greece, swallows are migratory birds that return to their breeding grounds from Africa in spring (March-April) and form pairs. Their breeding season lasts from March to June, and the pair builds their nest using mud pellets, feathers, grass, and other materials forming a cup. Usually, the nest is built next to human-made structures and the pair lives close to humans. The female typically lays 3-6 eggs that hatch in 15-20 days. The chicks fledge their nest when they are around 3 weeks old. At the end of August, before autumn begins, the swallows migrate back to the African continent due to the warmer climate there and the scarcity of insects at that time in the European continent [44]. Based on the patient's description of the swallows' exterior features, the endemic swallow species observed in the region [45], and on the nest site (window sill), it can be deduced that the most probable swallow species was Delichon urbicum. In the two previous reports of D. gallinae infesting swallows' nest, the swallows' species were identified as Hirundo rustica in Iran [27] and Delichon urbicum in France [12].

The D. gallinae haplotype isolated in the present study fits in haplogroup A among other PRM haplotypes identified in Greece and belongs to D. gallinae sensu stricto cryptic species. However, it is quite distant (32 mutational steps) from the two D. gallinae haplotypes that have been previously isolated from swallows in France (haplogroup D). This genetic distance can be explained by the fact that swallows are rare hosts for D. gallinae and only two other haplotypes from swallows have been studied. The close similarity between the haplotype identified in this study and other PRM haplotypes found in Greek hens suggests that the swallows may have acquired the mites after being in contact with hen facilities. Certain strains of D. gallinae mites can be transferred between hosts easily and continue to feed and reproduce on the new host without any problem [12].

The haplotype isolated from swallows in Kefalonia is identical to the haplotypes identified in PRMs isolated from hens in Portugal. These two places are almost $2500 \mathrm{~km}$ apart. Swallows have been shown to migrate to Portugal from Africa in February-June and travel large distances until they arrive at their breeding ground [46]. Since D. gallinae do not live on the hosts, but rather on their nests [27], it is unlikely that the mites identified in this study survived on the swallows at such large distance so as to be transferred from Portugal to Greece. One possible explanation would be that laying hens in Greece and 
Portugal might have been infested with the same $D$. gallinae haplotypes which was then transferred through the international trade of contaminated hens and equipment $[15,17]$. Furthermore, when building their new nests swallows tend to use materials from old abandoned nests [44] that, in this case, could possibly have been infested with mites.

In addition, swallow nests are sometimes found outside poultry facilities [12,27]. As PRM prevalence in northern Greek laying hen farms has been recently reported to be $100 \%$ [47] and, the situation is likely to be similar in hen houses in Kefalonia, it is highly probable that the swallows in Kefalonia acquired the D. gallinae mites from a hen house when scavenging for nest materials.

Finally, this case further illustrates the need to consider gamasoidosis in the differential diagnosis of pruritic dermatitis with erythematous papules, excoriations, and urticaria-like plaques, even when they occur in patients living in a built environment in the absence of any poultry housing facilities. In urban areas, aside from sparrows, starlings and pigeons, nesting or roosting of migratory birds, such as swallows, may be a source of concern in human medicine and one health approaches.

\section{Conclusions}

Gamasoidosis remains an underdiagnosed pathological entity, often overlooked despite the increasing number of reported cases, especially in urban areas [25,26]. Aside from the hens and pigeons that are the typical hosts for D. gallinae in egg-laying farms and the urban environment, respectively, this case demonstrates that one should consider swallows (Hirundinidae) as a potential host of this ectoparasite. Future research should focus on isolating D. gallinae mites from laying hen farms in Kefalonia and compare their haplotypes with the one identified from the swallows. Consequently, homeowners in breeding areas should be warned to be especially careful when they see normally harmless swallow nests on or around their homes, which may increase the risk of infestation with PRM and therefore spread avian mite dermatitis, particularly in late spring and early summer.

Supplementary Materials: The following are available online at https:/ / www.mdpi.com/2076-081 7/10/3/299/s1, Figure S1: Medical history questionnaire. Table S1: Accession numbers and countries of origin for each haplotype.

Author Contributions: Conceptualization, E.P.; methodology, G.S., S.M., A.T., K.T., and C.C.; software, S.M. and A.T.; validation, E.P. and G.S.; formal analysis, G.S., S.M., and A.T.; investigation, E.P., G.S., and K.T.; resources, E.P. and A.T.; data curation, G.S. and S.M.; writing-original draft preparation, G.S.; writing—-review and editing, G.S., S.M., K.T., C.C., A.T., and E.P.; visualization, E.P. and G.S.; supervision, E.P.; project administration, E.P. All authors have read and agreed to the published version of the manuscript.

Funding: This research received no external funding.

Institutional Review Board Statement: Ethical review and approval were waived for this study, due to fact that it is a Case Report and not a Research Study. There was no interaction with the swallows or harm caused to them.

Informed Consent Statement: Written informed consent has been obtained from the patient to publish this paper.

Data Availability Statement: Publicly available datasets were analyzed in this study. This data can be found here: https:/ /www.ncbi.nlm.nih.gov/genbank/ (accessed on 5 January 2021).

Acknowledgments: All authors are thankful to the patient, for cooperating, providing us with the information needed, and allowing us to publish the present Case Report.

Conflicts of Interest: The authors declare no conflict of interest. 


\section{References}

1. Tomley, F.M.; Sparagano, O. Spotlight on avian pathology: Red mite, a serious emergent problem in layer hens. Avian Pathol. 2018, 47, 533-535. [CrossRef]

2. Sleeckx, N.; Van Gorp, S.; Koopman, R.; Kempen, I.; Van Hoye, K.; De Baere, K.; Zoons, J.; De Herdt, P. Production losses in laying hens during infestation with the poultry red mite Dermanyssus gallinae. Avian Pathol. 2019, 48, S17-S21. [CrossRef]

3. Valiente Moro, C.; Chauve, C.; Zenner, L. Experimental infection of Salmonella enteritidis by the poultry red mite, Dermanyssus gallinae. Vet. Parasitol. 2007, 146, 329-336. [CrossRef]

4. Valiente Moro, C.; De Luna, C.J.; Tod, A.; Guy, J.H.; Sparagano, O.A.E.; Zenner, L. The poultry red mite (Dermanyssus gallinae): A potential vector of pathogenic agents. Exp. Appl. Acarol. 2009, 48, 93-104. [CrossRef]

5. Chirico, J.; Eriksson, H.; Fossum, O.; Jansson, D. The poultry red mite, Dermanyssus gallinae, a potential vector of Erysipelothrix rhusiopathiae causing erysipelas in hens. Med. Vet. Entomol. 2003, 17, 232-234. [CrossRef] [PubMed]

6. Circella, E.; Pugliese, N.; Todisco, G.; Cafiero, M.A.; Sparagano, O.A.E.; Camarda, A. Chlamydia psittaci infection in canaries heavily infested by Dermanyssus gallinae. Exp. Appl. Acarol. 2011, 55, 329-338. [CrossRef] [PubMed]

7. Oh, S.-I.; Do, Y.J.; Kim, E.; Yi, S.W.; Yoo, J.G. Prevalence of poultry red mite (Dermanyssus gallinae) in Korean layer farms and the presence of avian pathogens in the mite. Exp. Appl. Acarol. 2020, 81, 223-238. [CrossRef] [PubMed]

8. George, D.R.; Finn, R.D.; Graham, K.M.; Mul, M.F.; Maurer, V.; Moro, C.V.; Sparagano, O.A. Should the poultry red mite Dermanyssus gallinae be of wider concern for veterinary and medical science? Parasit. Vectors 2015, 8. [CrossRef] [PubMed]

9. Sommer, D.; Heffels-Redmann, U.; Köhler, K.; Lierz, M.; Kaleta, E.F. Rolle der Roten Vogelmilbe (Dermanyssus gallinae) bei der Übertragung von aviärem Influenza-A-Virus. Tierarztl. Prax. Ausg. G Grosstiere Nutztiere 2016, 44, 26-33. [CrossRef]

10. Raele, D.A.; Galante, D.; Pugliese, N.; La Salandra, G.; Lomuto, M.; Cafiero, M.A. First report of Coxiella burnetii and Borrelia burgdorferi sensu lato in poultry red mites, Dermanyssus gallinae (Mesostigmata, Acari), related to urban outbreaks of dermatitis in Italy. New Microbes New Infect. 2018, 23, 103-109. [CrossRef]

11. Melter, O.; Arvand, M.; Votýpka, J.; Hulínská, D. Bartonella quintana transmission from mite to family with high socioeconomic status. Emerg. Infect. Dis. 2012, 18, 163-165. [CrossRef]

12. Roy, L.; Dowling, A.P.G.; Chauve, C.M.; Lesna, I.; Sabelis, M.W.; Buronfosse, T. Molecular phylogenetic assessment of host range in five Dermanyssus species. Exp. Appl. Acarol. 2009, 48, 115-142. [CrossRef] [PubMed]

13. Roy, L.; Dowling, A.P.G.; Chauve, C.M.; Buronfosse, T. Delimiting species boundaries within Dermanyssus Dugès, 1834 (Acari:Dermanyssidae) using a total evidence approach. Mol. Phylogenet Evol. 2009, 50, 446-470. [CrossRef] [PubMed]

14. Roy, L.; Chauve, C.M. Historical review of the genus Dermanyssus Dugès, 1834 (Acari: Mesostigmata: Dermanyssidae). Parasite 2007, 14, 87-100. [CrossRef]

15. Øines, Ø.; Brannstrom, S. Molecular investigations of cytochrome c oxidase subunit I (COI) and the internal transcribed spacer (ITS) in the poultry red mite, Dermanyssus gallinae, in northern Europe and implications for its transmission between laying poultry farms. Med. Vet. Entomol. 2011, 25, 402-412. [CrossRef]

16. Pezzi, M.; Leis, M.; Chicca, M.; Roy, L. Gamasoidosis caused by the special lineage L1 of Dermanyssus gallinae (Acarina: Dermanyssidae): A case of heavy infestation in a public place in Italy. Parasitol. Int. 2017, 66, 666-670. [CrossRef] [PubMed]

17. Budria, A.; Candolin, U. How does human-induced environmental change influence host-parasite interactions? Parasitology 2013, 141, 462-474. [CrossRef]

18. Sparagano, O.A.E.; George, D.R.; Harrington, D.W.J.; Giangaspero, A. Significance and Control of the Poultry Red Mite, Dermanyssus gallinae. Annu. Rev. Entomol. 2014, 59, 447-466. [CrossRef]

19. Kilpinen, O. How to obtain a bloodmeal without being eaten by a host: The case of poultry red mite, Dermanyssus gallinae. Physiol. Entomol. 2005, 30, 232-240. [CrossRef]

20. Regan, A.M. Nosocomial Dermatitis and Pruritus Caused by Pigeon Mite Infestation. Arch. Intern. Med. 1987, 147, 2185. [CrossRef]

21. Bellanger, A.P.; Bories, C.; Foulet, F.; Bretagne, S.; Botterel, F. Nosocomial Dermatitis Caused by Dermanyssus gallinae. Infect. Control. Hosp. Epidemiol. 2008, 29, 282-283. [CrossRef] [PubMed]

22. Cafiero, M.A.; Galante, D.; Camarda, A.; Giangaspero, A.; Sparagano, O. Why dermanyssosis should be listed as an occupational hazard. Occup. Environ. Med. 2011, 68, 628. [CrossRef] [PubMed]

23. Haag-Wackernagel, D. Parasites from feral pigeons as a health hazard for humans. Ann. Appl. Biol. 2005, 147, 203-210. [CrossRef]

24. Wambier, C.G.; de Farias Wambier, S.P. Gamasoidosis illustrated: From the nest to dermoscopy. Bras. Derm. 2012, 87, 926-927. [CrossRef] [PubMed]

25. Kavallari, A.; Küster, T.; Papadopoulos, E.; Hondema, L.S.; Øines, Ø.; Skov, J.; Sparagano, O.; Tiligada, E. Avian mite dermatitis: Diagnostic challenges and unmet needs. Parasite Immunol. 2018, 40, e12539. [CrossRef]

26. Santana, A.P.; Cardoso, A.E.C.; Passos, R.T.; Ferreira, Í.S.C. Case for diagnosis. Erythematous and pruritic papules on forearms. Bras. Derm. 2020, 95, 250-251. [CrossRef]

27. Ghalehjoughi, E.M.; Tavassoli, M.; Naem, S. Dermanyssus gallinae (Acari, Mesostigmata) in the Barn Swallow (Hirundo rustica) nests in Urmia suburb, North West of Iran. Persian J. Acarol. 2017, 6. [CrossRef]

28. Moss, W.W. An Illustrated Key To The Species Of The Acarine Genus Dermanyssus (Mesostigmata: Laelapoidea: Dermanyssidae)1. J. Med. Entomol. 1968, 5, 67-84. [CrossRef] 
29. Moss, W.W. The Mite Genus Dermanyssus: A Survey, with Description of Dermanyssus trochilinis, N. Sp., And a Revised Key to the Species (Acari: Mesostigmata: Dermanyssidae). J. Med. Entomol. 1978, 14, 627-640. [CrossRef]

30. Di Palma, A.; Giangaspero, A.; Cafiero, M.A.; Germinara, G.S. A gallery of the key characters to ease identification of Dermanyssus gallinae (Acari: Gamasida: Dermanyssidae) and allow differentiation from Ornithonyssus sylviarum (Acari: Gamasida: Macronyssidae). Parasit. Vectors 2012, 5. [CrossRef]

31. Chu, T.T.H.; Murano, T.; Uno, Y.; Usui, T.; Yamaguchi, T. Molecular epidemiological characterization of poultry red mite, Dermanyssus gallinae, in Japan. J. Vet. Med. Sci. 2015, 77, 1397-1403. [CrossRef]

32. Karp-Tatham, E.; Küster, T.; Angelou, A.; Papadopoulos, E.; Nisbet, A.J.; Xia, D.; Tomley, F.M.; Blake, D.P. Phylogenetic Inference Using Cytochrome C Oxidase Subunit I (COI) in the Poultry Red Mite, Dermanyssus gallinae in the United Kingdom Relative to a European Framework. Front. Vet. Sci. 2020, 21, 553. [CrossRef]

33. Kearse, M.; Moir, R.; Wilson, A.; Stones-Havas, S.; Cheung, M.; Sturrock, S.; Buxton, S.; Cooper, A.; Markowitz, S.; Duran, C.; et al. Geneious Basic: An integrated and extendable desktop software platform for the organization and analysis of sequence data. Bioinformatics 2012, 28, 1647-1649. [CrossRef] [PubMed]

34. Thompson, J.D.; Higgins, D.G.; Gibson, T.J. CLUSTAL W: Improving the sensitivity of progressive multiple sequence alignment through sequence weighting, position-specific gap penalties and weight matrix choice. Nucleic Acids Res. 1994, 22, 4673-4680. [CrossRef] [PubMed]

35. Rozas, J.; Ferrer-Mata, A.; Sánchez-DelBarrio, J.C.; Guirao-Rico, S.; Librado, P.; Ramos-Onsins, S.E.; Sánchez-Gracia, A. DnaSP 6: DNA Sequence Polymorphism Analysis of Large Data Sets. Mol. Biol. Evol. 2017, 34, 3299-3302. [CrossRef] [PubMed]

36. Kumar, S.; Stecher, G.; Li, M.; Knyaz, C.; Tamura, K. MEGA X: Molecular Evolutionary Genetics Analysis across Computing Platforms. Mol. Biol. Evol. 2018, 35, 1547-1549. [CrossRef] [PubMed]

37. Drummond, A.J.; Suchard, M.A.; Xie, D.; Rambaut, A. Bayesian Phylogenetics with BEAUti and the BEAST 1.7. Mol. Biol. Evol. 2012, 29, 1969-1973. [CrossRef]

38. Rambaut, A.; Drummond, A.J.; Xie, D.; Baele, G.; Suchard, M.A. Posterior Summarization in Bayesian Phylogenetics Using Tracer 1.7. Syst. Biol. 2018, 67, 901-904. [CrossRef] [PubMed]

39. Rambaut, A.; Drummond, A.J. Molecular Evolution, Phylogenetics and Epidemiology. FigTree v1.3.1. Available online: http: / / tree.bio.ed.ac.uk/software/figtree/ (accessed on 5 January 2021).

40. Bandelt, H.J.; Forster, P.; Rohl, A. Median-joining networks for inferring intraspecific phylogenies. Mol. Biol. Evol. 1999, 16, 37-48. [CrossRef]

41. Cafiero, M.A.; Barlaam, A.; Camarda, A.; Radeski, M.; Mul, M.; Sparagano, O.; Giangaspero, A. Dermanysuss gallinae attacks humans. Mind the gap! Avian Pathol. 2019, 48, S22-S34. [CrossRef]

42. Sargison, N.D.; Jacinavicius, F.C.; Fleming, R.H.; Chaudhry, U.N.; Costa-Junior, L.M. Investigation of a gamasid mite infestation in a UK textile mill caused by Dermanyssus gallinae (DeGeer, 1778) (Mesostigmata: Dermanyssidae) special lineage L1. Parasitol. Int. 2020, 78, 102146. [CrossRef] [PubMed]

43. Prouteau, C.; Ameline, M.; Roy, L.; Delaunay, P.; Gangneux, J.-P.; Dupuy, A. Prurigo à Dermanyssus gallinae. Ann. Derm. Vénéréol. 2020, 147, 119-122. [CrossRef] [PubMed]

44. Turner, A.K.; Rose, C. A Handbook to the Swallows and Martins of the World, 1st ed.; Christopher Helm: London, UK, 1989 ; pp. 12-29.

45. Hölzinger, J. Bruten der Mehlschwalbe Delichon urbicum auf einem Fährschiff zwischen Poros (Kefalonia) und Killini (Peloponnes, Griechenland) mit Bemerkungen zu weiteren Bruten auf Schiffen in Europa. Ornithol. Beob. 2012, 109, 177-184.

46. Ambrosini, R.; Borgoni, R.; Rubolini, D.; Sicurella, B.; Fiedler, W.; Bairlein, F.; Baillie, S.R.; Robinson, R.A.; Clark, J.A.; Spina, F.; et al. Modelling the Progression of Bird Migration with Conditional Autoregressive Models Applied to Ringing Data. PLoS ONE 2014, 9, e102440. [CrossRef] [PubMed]

47. Arsenopoulos, K.; Angelou, A.; Papadopoulos, E. Dermanyssus gallinae-A ghost ectoparasite for the Greek laying hen industry: Results of a preliminary study. Bulg. J. Vet. Med. 2017, 20, 383-388. 